\title{
BLOOD COAGULATION AND THE CLINICAL PATHOLOGIST
}

Confronted by the contents of this issue, the reader may be surprised, even dismayed, by the preponderance of papers on blood coagulation, and he may protest that the usual balance between the branches of pathology is also upset. (This will be rectified in future issues.) He may feel that the importance of this subject to him, as a clinical pathologist, is unlikely to justify the effort required to understand all the latest advances. The Editorial Board, in an attempt to encourage such an effort, has decided to include these words of editorial explanation.

Research in blood clotting has been mainly academic in the sense that those engaged in it have been more interested in the problem for its own sake than in practical applications. It is characteristic of this, a very usual type of situation, that when practical applications do come they advance not smoothly but in rushes. Throughout a period of nearly 40 years of active research the only test of clotting efficiency made available to the pathologist was the estimation of the simple coagulation time of the blood. Then, in 1935, Quick introduced his " prothrombin time" test, and a tremendous impetus was given to the investigation of coagulation disorders and, reflexly, to academic research. In this new climate of thought the isolation of vitamin $K$, an understanding of the mechanism of haemorrhage in jaundice, the introduction of the anticoagulant drugs, and the discovery of factor $\mathrm{V}$ followed each other within the space of a few years. All of these discoveries were directly or indirectly the outcome of this technically simple test, which, despite all recent advances, remains the only satisfactory method for controlling anticoagulant therapy. A similar but smaller impetus can be traced to the prothrombin consumption test, applied by Quick and Favre-Gilly (1949), which has led to the recognition of minor degrees of haemophilia, of the clotting defect caused by thrombocytopenia, to interest in the coagulant properties of serum, and thus to the discovery of factor VII. No pathologist could question the importance of these events.

Certain workers in this country now believe that another period of acceleration may be approaching. The fresh impetus is expected to be derived from a new test, the thromboplastin generation test, and from a new appreciation of an old idea, the idea that shed blood produces its own thromboplastin as the first essential stage in coagulation, which was put forward quite clearly by Collingwood and MacMahon in 1912. Though Lenggenhager (1936), Macfarlane (1942), Quick (1947), Brinkhous (1947), and Milstone (1948) all produced arguments in favour of the view that thromboplastin is formed in the blood by some reaction involving two or more factors, the idea did not gain general acceptance. Perhaps the false assumption, that because the clotting time of normal blood is comparatively long its content of thromboplastin must be very small, led workers to believe that blood thromboplastin (if it existed) was unimportant.

Recently, a study of the formation of thrombin in whole blood convinced workers in Oxford that not only is the generation of thromboplastin the major factor controlling the normal coagulation time, but this thromboplastin once formed is extremely powerful. Some practical results of this study are already apparent. Macfarlane and Biggs describe (p. 3) the "thrombin generation test" and its value in revealing and differentiating some causes of defective thromboplastin production such as a deficiency of antihaemophilic globulin or platelets. Pitney and Dacie (p. 9) put forward the equally useful results they have obtained with a convenient modification of this test. But the most important result 
was a stimulation of efforts to demonstrate and measure by direct methods the production of blood thromboplastin. By good fortune two naturally occurring conditions presented themselves during the work, which provided both the means for achieving the objective and additional information on the mechanisms involved. The first of these conditions was represented by a case of uncomplicated prothrombin deficiency, a very rare occurrence, since most patients with hypoprothrombinaemia lack factor VII as well. The naturally prothrombin-free blood of this patient enabled Biggs and Douglas (p. 15) to devise a method for estimating prothrombin which is probably less influenced than present methods by the deficiency of other factors that usually accompanies prothrombin deficiency. It was also possible, in the absence of the complicating effect of thrombin formation, to demonstrate for the first time the unequivocal appearance of a powerful thromboplastin in the plasma (Biggs, 1952). Further investigations followed, and it was found that this thromboplastin production requires the presence of the platelets, calcium, antihaemophilic globulin, and factor VII (Biggs and Macfarlane, 1953 ; Biggs, Douglas, and Macfarlane, 1953). Almost immediately afterwards the condition described as "Christmas disease" presented itself, and it was discovered that another factor, not clearly recognized previously, is an essential part of this system, and by its deficiency causes a haemophilia-like diathesis (Biggs et al., 1952). The most recent observations suggest also that factor $\mathrm{V}$, previously considered to be an accelerator of prothrombin conversion, is concerned in thromboplastin generation. So the old and much battered classical theory of coagulation seems now to be restored to its original form, but behind the term "thromboplastin" there stands this newly recognized system of at least five factors.
The immediate practical outcome of this latest theoretical development is the "thromboplastin generation test," the application of which is described by Biggs and Douglas (p. 23). This test allows the activity of each of the known factors involved in thromboplastin production to be assayed separately. It has already revealed the essential difference between haemophilia and Christmas disease, the existence of a qualitative abnormality of the platelets, of minor deficiencies of antihaemophilic globulin, and the action of a variety of naturally occurring inhibitors described both in this paper and by Hougie (p. 30). The method for estimating heparin (p. 39) should also prove a great practical aid in the management of cases of thrombosis, and the preliminary report on the transfusion of platelets (p. 41) holds out some hope for the control of haemorrhage in clearcut cases of thrombocytopenia.

It is legitimate to hope that these are only the beginnings of a new period of practical and academic advance in problems of haemorrhage and thrombosis.

\section{REFERENCES}

Biggs, R. (1952). Nature, Lond., 170, 280.

— Douglas, A. S., and Macfarlane, R. G. (1953). $J$. Physiol., Lond. In the press.

- Dacie, J. V., Pitney, W. R., Merskey, C., and O'Brien, J. R. (1952). Brit. med. J., 2, 1378. and Macfarlane, R. G. (1953). Human Blood Coagulation and its Disorders. Blackwell, Oxford.

Brinkhous, K. M. (1947). Proc. Soc. exp. Biol., N.Y., 66, 117.

Collingwood, B. J., and MacMahon, M. T. (1912). J. Physiol., Lond., 45, 119.

Lenggenhager, K. (1936). Klin. Wschr., 15, 1835.

Macfarlane, R. G. (1942). Proc. roy. Soc. Med., 35, 410.

Milstone, J. H. (1948). J. gen. Physiol., 31, 301.

Quick, A. J. (1935). J. biol. Chem., 109, lxxiii.

—_ (1947). Amer. J. med. Sci., 214, 272.

_ and Favre-Gilly, J. E. (1949). Blood, 4, 1281. 